\title{
EXPERIMENTAL STUDY OF FILAMENTATION AND SUPERCONTINUUM GENERATION IN LASER-MODIFIED FUSED SILICA
}

\author{
D. Paipulas, A. Balskienè, and V. Sirutkaitis \\ Laser Research Center, Department of Quantum Electronics, Faculty of Physics, Vilnius University, Sauletekio 10, LT-10223 Vilnius, \\ Lithuania \\ E-mail: domas.paipulas@ff.vu.lt
}

Received 29 November 2012; accepted 20 December 2012

\begin{abstract}
In this paper we present experimental results on the behaviour of light supercontinuum generation and filamentation when ultrafast laser induced material modifications are accumulating in fused silica. We show that due to material modification supercontinuum spectrum starts to shrink and its intensity rapidly decreases; this rate is highly affected by the laser pulse repetition rate. The filament tends to split along the beam propagating path resulting in inhomogeneous distribution of the modified material.
\end{abstract}

Keywords: femtosecond micromachining, the material modification, filamentation, supercontinuum

PACS: 42.62.Cf, 42.65.Sf, 42.70.Ce

\section{Introduction}

Since the advent of ultrafast lasers, femtosecond laser pulses have become a unique tool in the arsenal of modern micromachining scientists. Many (if not all!) materials of different types and consistencies can be in one or another way affected by an ultrafast laser pulse. Especially promising applications are those that involve modification of transparent materials. After the seminal work by Davis et al. in 1996 [1], where it was first demonstrated that it is possible to induce highly localized refractive index variations in the volume of glassy material and create burred waveguides, many techniques have been developed and various photonic devices, passive and active, were demonstrated in the wide variety of transparent materials (a full review on this subject could be found in Ref. [2] and references within it).

In order to modify the material, an ultrafast laser beam has to be sharply focused into the transparent matter. In this arrangement sufficient intensities can be achieved to initiate localized nonlinear absorption that consequently leads to the change of the materials' optical properties. Modified zone sizes depend on material properties, laser parameters and focusing conditions, but typically their diameters tend to be in micrometre or sub-micrometre ranges. By employing various laser patterning methods (usually a conventional point-by-point laser recording technique) modified zones can be merged and arranged in specific orders and form a desired photonic device. However, if the photonic device has to be big in size, such recording technique is not efficient as the inscription process becomes too long.

One way to increase modification size is to exploit the pulse filamentation phenomenon for recording purposes. When a femtosecond pulse is focused into nonlinear matter with a lens of relatively low numerical aperture, its intensities can reach critical values capable to initiate pulse spatial-temporal transformations. Well-known examples of such transformations are spectral broadening (supercontinuum generation), conical emission, filamentation, and many other effects. These effects are well documented in literature and can be found in several recent reviews 
and books [3, 4]. In the filament propagation regime, a beam propagates through media without any diffraction while the main part of laser energy is contained in a small filament core. If laser intensities are quite high, material damage or modification can be achieved [5, 6]. These damage tracks are much bigger in size than those produced with a convenient method, and can be an attractive method for various photonic device formation [7].

The scale of spatial-temporal effects happening with a propagating pulse mostly depend on laser power and material nonlinear properties, which tend to change after material modification. Unfortunately, in most spatial-temporal pulse transformation studies, material modification is an undesirable result and is avoided at any chance. Thus, knowledge about modification influence on nonlinear effects and vice verse is pretty scarce. In this paper we present results on the influence of material modifications on spatial-temporal effects, particularly supercontinuum generation and filament formation taking place in fused silica.

\section{Experiment}

An experimental set-up used for inducing modification and investigation of the nonlinear process is shown in Fig. 1. We used the Yb:KGW laser system (Pharos, Light Conversion Ltd.) as a femtosecond laser source. The laser central wavelength was $1030 \mathrm{~nm}$ and its pulse duration $300 \mathrm{fs}$, while pulse repetition rate could be varied up to $300 \mathrm{kHz}$. A laser beam was focused into the sample with the $200 \mathrm{~mm}$ focal length lens (laser beam diameter before the lens was $3.9 \mathrm{~mm}$ ). The sample was made from UV grade synthetic fused silica (Schott Lithosil) that had

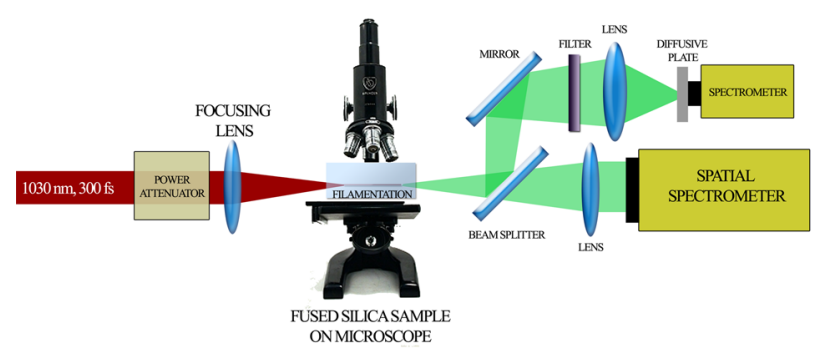

Fig. 1. Experimental set-up for filament formation and supercontinuum generation in fused silica by using the Pharos laser system.
$5 \mathrm{~mm}$ thickness. The confocal parameter of the lens was $\sim 8 \mathrm{~mm}$ so the focus could cover the full sample thickness; however, the sample was positioned at the place where the longest filament was formed (in this case a paraxial geometrical focus was $\sim 4 \mathrm{~mm}$ bellow the sample surface).

The spectral broadening effects were investigated with the fibre spectrometer (AvaSpec2048, Avantes). The light from the supercontinuum was guided through the infrared filter for fundamental wavelength attenuation purposes and focused on a diffusive plate in order to integrate the spatial spectra before guiding the light into the spectrometer's input. For spatial spectrum measurements we used a spatial spectrometer Positive Light (Spectra Phys$i c s$, grating 142 grooves $/ \mathrm{mm}$ ). Also, filament formation in the glass was observed using a microscope in real time.

Filament formation experiments were carried out using different pulse repetition rates and pulse energies. Threshold energy for filament appearance (as well as supercontinuum) was $3.5 \mu \mathrm{J}$ at $100 \mathrm{kHz}$. Similar energy was obtained with different pulse repetition rates. The critical peak power for filament formation is $4.1 \mathrm{MW}$ in fused silica (calculated using $P_{\text {cr }}=0.61^{2} \pi \lambda^{2} /\left(8 n_{0} n_{2}\right)$, where $\lambda$ is laser wavelength, $n_{0}$ and $n_{2}$ are linear and nonlinear refractive indexes, which are equal to 1.45 and $3.5 \cdot 10^{-20} \mathrm{~m}^{2} / \mathrm{W}$, respectively), and this corresponds to $1.2 \mu \mathrm{J}$ energy (at $100 \mathrm{kHz}$ ). So in our experiment the observable supercontinuum started to appear when $P=2.9 P_{\mathrm{cr}}$. When the peak power reached $P=7 P_{\text {cr }}$ the homogeneous supercontinuum image decreased and interferometric patterns - evidence of multiple filament formation - started to appear. The most stable supercontinuum was achieved using peak powers 5-6 times greater than the critical value.

\section{Modification influence on supercontinuum spectrum}

\subsection{Supercontinuum in fused silica}

The stable continuum can be generated in fused silica by keeping the sample constantly in motion in the perpendicular-to-laser-beam direction. This procedure prevents the appearance of accumulative damage defects and modifications in the material and supercontinuum shape is determined only by initial material, and laser pulse in- 
teraction processes. A typical supercontinuum generated using this technique with $300 \mathrm{fs}$ duration and $1030 \mathrm{~nm}$ wavelength laser pulses is shown in Fig. 2 . Such supercontinuum has a peculiar property: its

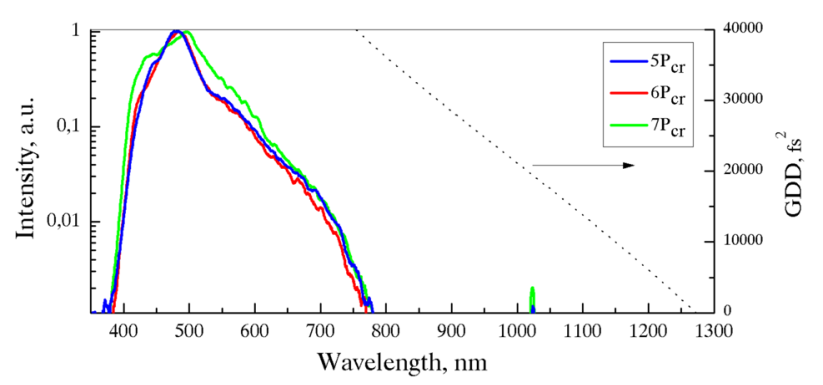

Fig. 2. Supercontinuum spectrum generated in fused silica with a $1030 \mathrm{~nm}$ wavelength femtosecond laser using different pulse powers (pump beam intensity is shown not to scale). The graph also shows group velocity dispersion curve modelled for the tested sample (colour online).

spectrum is completely isolated from the pump beam. Such feature is unexpected as in most supercontinuum formation theories and experiments it is demonstrated that spectral broadening originates from the pump wavelength and expands to both sides of the spectrum (with stronger broadening towards a bluer spectral region), and isolated, blue-shifted spectral regions can be possible only when pump wavelength is deep in an anomalous dispersion region [8, 9]. However, in our experiment pump wavelength is in a normal dispersion region (see Fig. 2). Faccio et al. also demonstrated a similar blue-shifted continuum in fused silica when pumped with picosecond, $1055 \mathrm{~nm}$ wavelength laser pulses [10]. They explain such continuum appearance through temporal pulse splitting effects which take place in normal dispersion media. As a continuum spectrum in our experiment has identical features, it is reasonable to assume that such temporal pulse splitting can develop with femtosecond laser pulses too.

\subsection{Modification induced supercontinuum spectrum variations}

When laser pulses expose one singular area of the material the supercontinuum spectrum starts to change. These changes are linked with the accumulation of material modifications in the exposed glass region. The radiating intensity of the supercontinuum starts to decrease, also the short-wavelength edge starts to move towards longer wavelengths. A typical spectral behaviour is shown in Fig. 3.

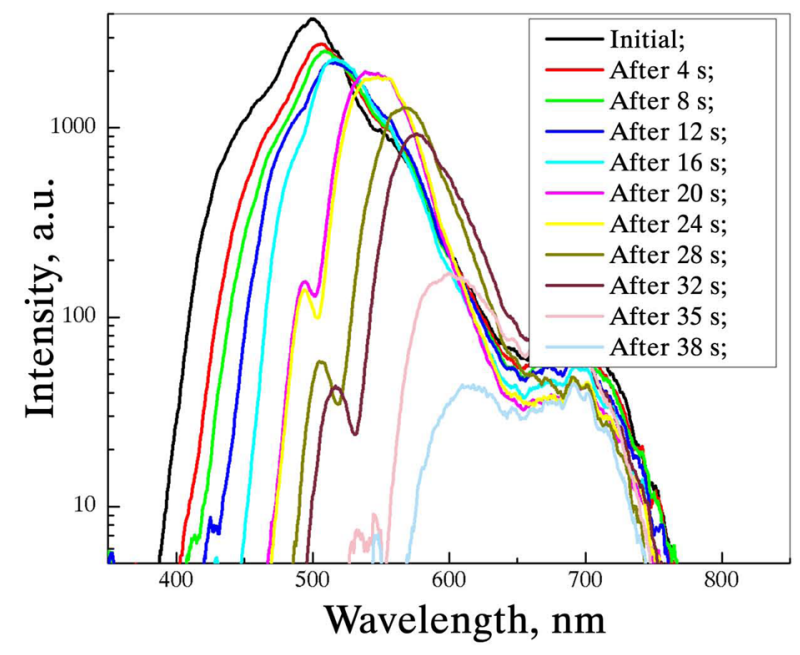

(a)

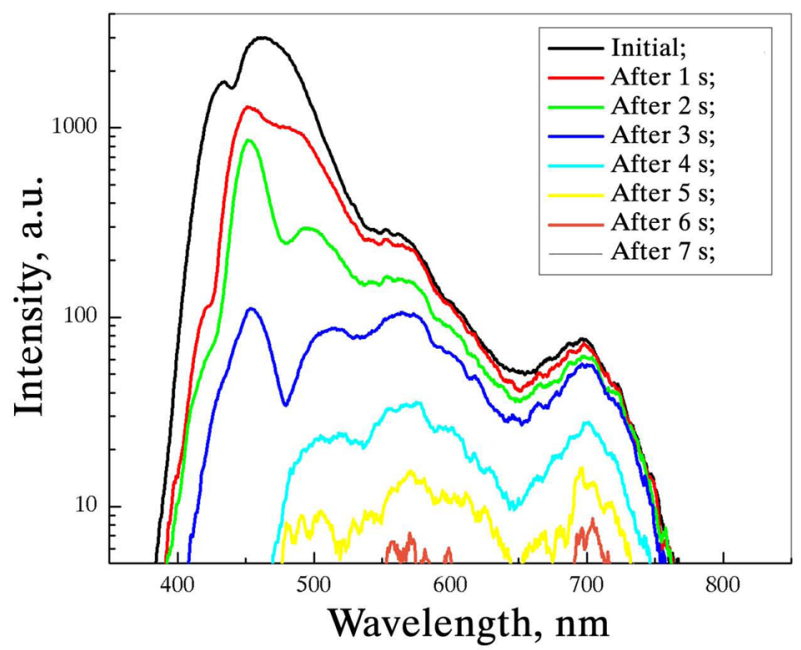

(b)

Fig. 3. Dynamics of supercontinuum spectra during exposition with $100 \mathrm{kHz}$ laser pulses. Pulse peak powers are: (a) $5 P_{\text {cr }}$ and (b) $4 P_{\text {cr }}$ (colour online). 
It is clear that when the pulse repetition rate is $100 \mathrm{kHz}$, modifications "shift" the supercontinuum edge from 400 to $550 \mathrm{~nm}$ in less than $40 \mathrm{~s}$. This time becomes shorter if pulse energies close to the supercontinuum generation threshold are used. When exposition time is long enough, the supercontinuum completely fades out and becomes undetectable.

The speed of spectrum intensity attenuation is closely linked to the pulse repetition rate. When the rate is sufficiently low $(<150 \mathrm{kHz})$, attenuation speed has statistical behaviour and could vary from several seconds to minutes. Such behaviour could be linked to the fluctuating laser power and nonuniform distribution of initial defects in the material. However, when the repetition rate is higher, attenuation speed becomes well defined. These results are shown in Fig. 4. It is clear from the graph that the supercontinuum starts to generate instantly (at lower repetition, supercontinuum intensity growth was observed during the first $200 \mathrm{~ms}$, however this growth was relatively small), and then a continuous exponential decay follows. At $160 \mathrm{kHz}$ continuum generation stops after $3.5 \mathrm{~s}$ (measured at $1 / \mathrm{e}^{2} \mathrm{lev}-$ el), while at $200 \mathrm{kHz}$ it takes $850 \mathrm{~ms}$, at $250 \mathrm{kHz}$ $250 \mathrm{~ms}$ and at $300 \mathrm{kHz} 150 \mathrm{~ms}$ (attenuation for this rate could not be fitted using an exponential decay curve as the decay is much faster). It is clear that the minimum number of pulses required to affect

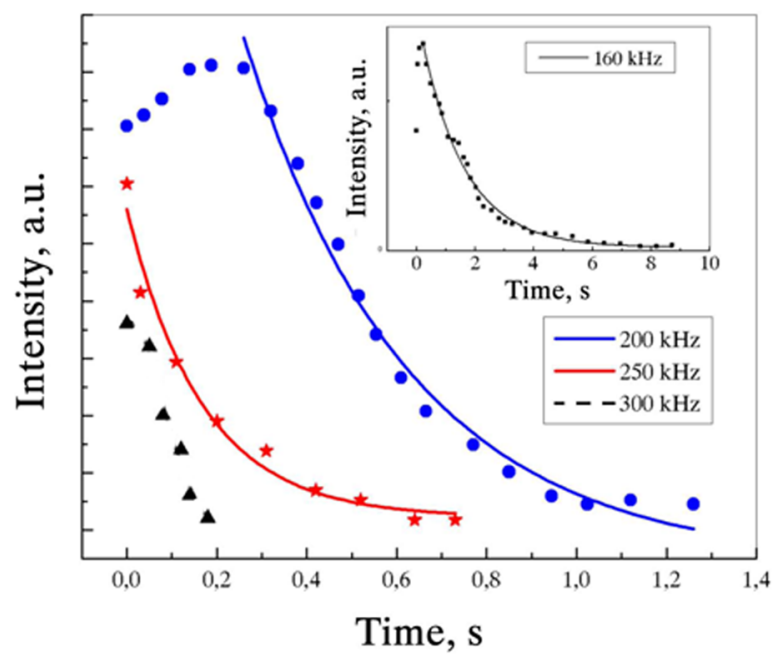

Fig. 4. Supercontinuum intensity dependence on exposition time at various pulse repetition rates. Pulse peak power $5 P_{\text {cr }}$. Curves are fitted using the exponential decay law (colour online). the material and prevent continuum generation decreases with the repetition rate increasing. To test that this decrease is not linked with thermal effects, we blocked the pump beam for several minutes and then re-exposed the same sample area, but no supercontinuum generation could be observed. This shows the presence of accumulation effects possibly caused by short-lived defects in the material. It is known that self-trapped excitons can efficiently be formed in fused silica. With a lifespan shorter than $1 \mathrm{~ms}$, these defects change the material's absorption properties and influence laser energy deposition into the material [11, 12]. Such defects can be the reason for the increased modification formation rate when modifying with high repetition rate pulses.

How do induced modifications affect supercontinuum spectrum changes? It is problematic to answer this question unambiguously, as the physics of supercontinuum formation is still negotiable. However, by analyzing supercontinuum generation theories it is possible to identify processes that can be influenced by material modification.

Using the theory devised by Faccio et al. the blueshifted supercontinuum isolated from the pump wavelength is caused by the self-generated X-wave that forms during temporal pulse splitting [10]. Such $\mathrm{X}$-wave travels in the material with a group velocity that is considerably lower than the velocity governed only by material dispersion. Such circumstance creates phase matching conditions, and the supercontinuum can be generated far from the pump wavelength. If we analyse supercontinuum's spatial spectrum shown in Fig. 5, we will see that, indeed, the X-shaped spectrum at the beginning of laser exposition is formed in the blue region. However, such spectral formation starts to fade after sufficient exposition. It is known that a refractive index tends to increase in laser modified areas in fused silica [13], thus light filament is capable to create a permanent waveguide. This waveguide can prevent the formation of an X-wave packet, as it will trap the light and limit conical radiation essential for X-wave formation. Such phenomenon could explain changes observed in the supercontinuum spectrum decaying $\mathrm{X}$-wave destroys the phase matching condition required for supercontinuum generation.

Also, modification appearance in glass could explain spectral shifts by using more traditional continuum generation models. It is commonly accepted 

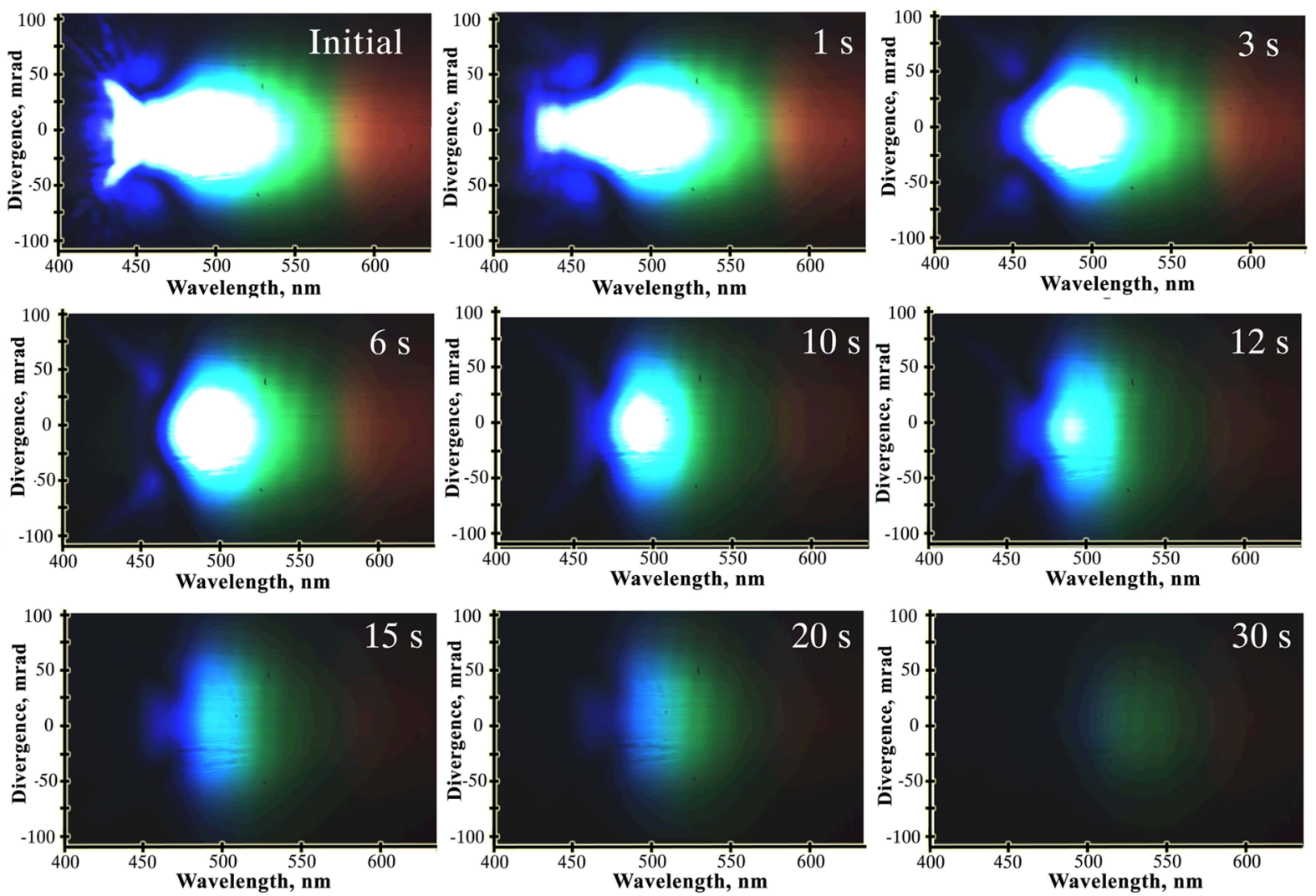

Fig. 5. Change of the spatial supercontinuum spectrum at various exposition times. Pulse peak power $7 P_{\text {cr }}$ pulse repetition rate $100 \mathrm{kHz}$ (colour online).

that the maximum supercontinuum broadening is determined by the intensity clamping effect. It means that maximum light intensity in the filament core is limited by nonlinear absorption. Also, this clamping intensity is a material property and can be expressed through the nonlinear refractive index. Blömer et al. showed that the nonlinear refractive index in lasermodified fused silica decreases fivefold 14. This should automatically reduce clamping intensity in the material and narrow the supercontinuum spectrum.

\section{Filament splitting and material modifications}

Filaments also tend to split into several parts along the pulse propagation direction in the material, as can be seen from Fig. 6. The splitting has statistical behaviour and is not always the same in identical conditions; however, the main tendencies are always the same: observable purplish filament splits into two, three or more parts depending on the focusing conditions or used pulse powers.
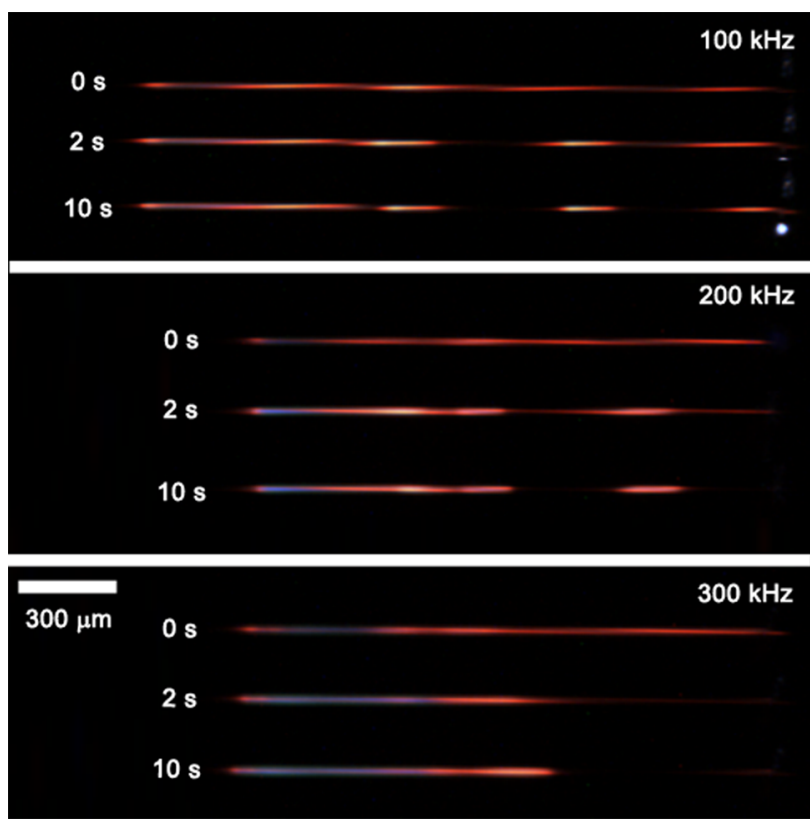

Fig. 6. Splitting of the filament in fused silica at different pulse repetition rates and exposure time. Pulse peak power $5 P_{\text {cr }}$. Laser is incident from the left (colour online). 
This splitting appears only in a single filament formation regime. When pulse power is higher than $9 P_{\mathrm{cr}}$, no such splitting is observed. Also, filament completely splits in the first $2 \mathrm{~s}$ of exposition and later does not change. It is observed even when supercontinuum generation is already faded out. So, the purplish glow of the filament is mainly caused by the luminescence effect (non-bridged oxygen deficiency centre fluoresces at $630 \mathrm{~nm}$ ) [13].

What causes the filament splitting? It was discovered earlier that the intense filament core is surrounded with a lower energy zone that acts like an energy reservoir for sustaining filament propagation [15]. Also, Dubietis et al. [16] showed that if the central filament part is blocked, the filament tends to reconstruct itself after some propagation distance. However, if the reservoir is blocked, filament propagation is completely destroyed. Modifications or material damage that forms in the filament path could act as obstacles disturbing filament propagation. The modifications formed by the filament created with $5 P_{\text {cr }}$ peak power pulses and $100 \mathrm{kHz}$ repetition rate are shown in Fig. 月 (microscope image taken in the phase contrast regime). The modifications are not homogeneous along the filament propagation path and actually duplicate the original splitting of the filament. By close inspection it can be seen that these modifications are not located precisely on the single beam propagation path, but are slightly shifted with respect to each other. This suggests that the filament was deconstructed and later underwent reformation in some (or several) particular places. No obvious obstacle (lightscattering centre or other material damage) can be identified along the beam propagation path; however, in experiments with higher beam powers the material damage could be clearly identified in the places where the filament breaks [17]. On the other hand, just a slight material modification, change of the linear and nonlinear refractive index could be sufficient for such filament breakage.

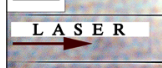

Fig. 7. Modifications in fused silica written with the laser filament. Average pulse power $5 P_{\mathrm{cr}}$, repetition rate $100 \mathrm{kHz}$. Scale bar is $100 \mu \mathrm{m}$ (colour online). Laser incidence direction shown by arrow.
Also, modification length and its distribution is not identical even in the same recording conditions. This can cause problems in applications where high modification placement accuracy is required. However, when accuracy is not the issue, modifications written with filaments could be beneficial, as it is possible to create various modification types in glass [18], also some technical tasks can be simplified using filament recording, as in the case of precise positioning of modifications in the optical fibre core [19].

In conclusion, we can state that with high repetition rate $\mathrm{Yb}: \mathrm{KGW}$ laser pulses it is possible to form modifications in fused silica by using light filament. Modifications influence nonlinear processes taking place in the material. The supercontinuum spectrum rapidly changes under continuous exposition, and filament splitting along the beam propagation path is also present, which fates uneven distribution of the formed modifications.

\section{References}

[1] K.M. Davis, K. Miura, N. Sugimoto, and K. Hirao, Writing waveguides in glass with a femtosecond laser, Opt. Lett. 21(21), 1729-1731 (1996).

[2] Femtosecond Laser Micromachining: Photonic and Microfluidic Devices in Transparent Materials, eds. R. Osellame, G. Cerullo, and R. Ramponi (Springer, 2012).

[3] A. Couairon and A. Mysyrowicz, Fermtosecond filamentation in transparent media, Phys. Rep. 441(2-4), 47-189 (2007).

[4] S.L. Chin, Femtosecond Laser Filamentation (Springer, 2010).

[5] L. Sudrie, A. Couairon, M. Franco, B. Lamouroux, B. Prade, S. Tzortzakis, and A. Mysyrowicz, Femtosecond laser-induced damage and filamentary propagation in fused silica, Phys. Rev. Lett. 89(18), 186601 (2002).

[6] N.T. Nguyen, A. Saliminia, W. Liu, S.L. Chin, and R. Vallée, Optical breakdown versus filamentation in fused silica by use of femtosecond infrared laser pulses, Opt. Lett. 28(17), 1591-1593 (2003).

[7] W. Watanabe, T. Tamaki, and K. Itoh, Filamentation in laser microprocessing and microwelding, Proc. SPIE 6733, 67332F (2007).

[8] E.O. Smetanina, A.E. Dormidonov, and V.P. Kandidov, Supercontinuum generation in filamentation of femtosecond laser pulse in fused silica, Proc. SPIE 8159, 81590L (2011).

[9] D.V. Skryabin and A.V. Gorbach, Colloquium: Looking at a soliton through 
the prism of optical supercontinuum, Rev. Mod. Phys 82, 1287-1299 (2010), http://dx.doi.org/10.1103/RevModPhys.82.1287.

[10]D. Faccio, A. Averchi, A. Lotti, M. Kolesik, J.V. Moloney, A. Couairon, and P. Di Trapani, Generation and control of extreme blueshifted continuum peaks in optical Kerr media, Phys. Rev. A 78(3), 033825 (2008).

[11] P. Martin, S. Guizard, P. Daguzan, G. Petite, P. D’Oliveira, P. Meynadier, and M. Perdrix, Subpicosecond study of carrier trapping dynamics in wide-band-gap crystals. Phys. Rev. B 55(9), 5799-5810 (1997).

[12]C. Itoh, K. Tanimura, and N. Itoh, Optical studies of self-trapped excitons in $\mathrm{SiO}_{2}$. J. Phys. C Solid State Phys. 21(26), 4693-4702 (1988).

[13]J. Chan, T. Huser, S. Risbud, and D. Krol, Modification of the fused silica glass network associated with waveguide fabrication using femtosecond laser pulses, Appl. Phys. A 76, 367-372 (2003).

[14] D. Blömer, A. Szameit, F. Dreisow, T. Schreiber, S. Nolte, and A. Tünnermann, Nonlinear refractive index of fs-laser-written waveguides in fused silica, Opt. Express 14(6), 2151-2157 (2006).
[15] S. Chin, A. Brodeur, S. Petit, O. Kosareva, and V. Kandidov, Filamentation and supercontinuum generation during the propagation of powerful ultrashort laser pulses in optical media white light laser), J. Nonlinear Opt. Phys. Mater. 8(1), 121146 (1999).

[16]A. Dubietis, E. Kučinskas, G. Tamošauskas, E. Gaižauskas, M.A. Porras, and P.D. Trapani, Selfreconstruction of light filaments, Opt. Lett. 29(24), 2893-2895 (2004).

[17] V. Sirutkaitis, E. Gaizauskas, V. Kudriashov, M. Barkauskas, V. Vaicaitis, R. Grigonis, and A.S. Piskarskas, Self-guiding supercontinuum generation and damage in bulk materials induced by femtosecond pulses, Proc. SPIE 4932, 346-357 (2003).

[18]I. Zergioti, K.D. Kyrkis, D.G. Papazoglou, and S. Tzortzakis, Structural modifications in fused silica induced by ultraviolet fs laser filaments, Appl. Surf. Sci. 253(19), 7865-7868 (2007).

[19] M. Bernier, S. Gagnon, and R. Vallée, Role of the $1 \mathrm{D}$ optical filamentation process in the writing of first order fiber Bragg gratings with femtosecond pulses at $800 \mathrm{~nm}$, Opt. Mater. Express 1(5), 832844 (2011).

\title{
ŠVIESOS GIJU FORMAVIMAS IR SUPERKONTINUUMO GENERAVIMAS FEMTOSEKUNDINIAIS LAZERIO IMPULSAIS MODIFIKUOTAME KVARCINIAME STIKLE
}

\author{
D. Paipulas, A. Balskienè, V. Sirutkaitis \\ Vilniaus universiteto Fizikos fakulteto Kvantines elektronikos katedra, Vilnius, Lietuva
}

\section{Santrauka}

Pateikiami eksperimentiniai rezultatai, gauti tiriant lazeriu modifikuotų darinių poveikį netiesiniams reiškiniams, vykstantiems lydyto kvarco stikle. Parodoma, kad dèl modifikacijų didelio pasikartojimo dažnio impulsais kuriamas superkontinuumas sparčiai silpsta, vyksta spektro siaurejjimas ir trumpabangio krašto slinkimas link ilgesniųjų bangų. Parodoma, kad šviesos gija lydytame kvarce skyla išilgai pluošto sklidimo krypties, o šis skilimas lemia nevienalyčius modifikuotos medžiagos darinius. 